\title{
Recurrent acute coronary syndrome and restenosis after percutaneous coronary intervention in a patient with idiopathic thrombocytopenic purpura: a case report and literature review
}

\author{
Ge Li-Sha', Chen Peng ${ }^{2}$ and Li Yue-Chun ${ }^{2 *}$
}

\begin{abstract}
Background: Platelets play a pivotal role in the pathogenesis of acute coronary syndrome (ACS) and acute and chronic complications following percutaneous coronary intervention (PCI). Platelet inhibition is a cornerstone in the management of these patients. Idiopathic thrombocytopenic purpura (ITP) is a bleeding disorder characterized by premature platelet destruction mediated by autoantibodies. The safety of antiplatelet therapy and $\mathrm{PCl}$ in patients who have ACS and ITP is unknown. The aim of the present study is to discuss the management strategies for patients who have ACS and ITP and to review limited data available in the literature.
\end{abstract}

Case presentation: We report the case of a patient with ITP who underwent three separate coronary interventions. The first $\mathrm{PCl}$ with stenting was performed in the left anterior descending artery 5 years ago while the patient suffered an anterior acute myocardial infarction, and the platelet count at admission was $90 \times 10^{9} / \mathrm{L}$. The patient presented with recurrent ACS and severe in-stent restenosis 5 years after the first $\mathrm{PCl}$, and the platelet count at admission was $18 \times 10^{9} / \mathrm{L}$, and elevated to $87 \times 10^{9} / \mathrm{L}$ after platelets transfusion. He was treated successfully with cutting balloon angioplasty under anticoagulation with unfractionated heparin and antiagregation with acetylsalicylic acid and clopidogrel. Four months later after cutting balloon angioplasty, the patient received an intracoronary stent when he once again presented with recurrent ACS in the setting of restenosis. The patient has been observed for 1.5 years without restenosis after the third $\mathrm{PCl}$.

Conclusion: We reviewed all the cases in the literature involving $\mathrm{PCl}$ and discussed the management strategies in patients with ITP and ACS. Available data suggest that PCI can be safe and feasible, and the risk-benefit equation of $\mathrm{PCl}$ procedures and antiplatelet therapies should be carefully evaluated, and the treatment should be individualized.

Keywords: Acute coronary syndrome, Idiopathic thrombocytopenic purpura, Percutaneous coronary intervention, Antiplatelet therapy

\footnotetext{
* Correspondence: liyuechun1980@sina.com

${ }^{2}$ Department of Cardiology, Second Affiliated Hospital of Wenzhou Medical University, 109 Xueyuan Road, Wenzhou, Zhejiang, China

Full list of author information is available at the end of the article
} 


\section{Background}

Platelets play a pivotal role in the pathogenesis of acute coronary syndrome (ACS) [1]. Treatment for ACS usually involves antiplatelet, anticoagulant, and antithrombotic therapy, and the performance of percutaneous coronary intervention (PCI) $[1,2]$. In addition, platelet aggregation also plays a crucial role in the pathogenesis of acute and chronic complications following PCI [1-3]. The combination of acetylsalicylic acid and thienopyridine derivatives is a mainstay in the management of patients undergoing PCI [1-3]. All of these medications are associated with bleeding sequelae and are generally contraindicated in patients with thrombocytopenia.

Idiopathic thrombocytopenic purpura (ITP) is an autoimmune syndrome involving antibody and cell-mediated destruction of platelets and suppression of platelet production that may predispose to bleeding [4]. Spontaneous mucocutaneous bleeding is common and death from hemorrhage occurs in approximately $5 \%$ of the ITP patients [4]. The decision to treat ITP is based on the platelet count, the degree of bleeding, and the patient's lifestyle. Many patients with ITP require no therapy and only careful monitoring. Treatment is indicated when platelets are $<30 \times 10^{9} / \mathrm{L}$, and is generally based on steroids and splenectomy [4]. Since the incidence of ITP is around 100 cases in 1 million persons per year, ACS patients with ITP are seen very rare. The safety of antiplatelet therapy and PCI in patients who have ACS and ITP is unknown, and to our knowledge, there are no guidelines or randomized studies to suggest treatment approaches in such patients.

We present here a case of a patient with ITP who experienced recurrent ACS and restenosis after PCI and we discuss the management strategies, including antiplatelet therapy.

\section{Case presentation}

A 75-year-old Chinese man was admitted to our hospital with increasing chest pain and dyspnea upon exertion. The chest pain developed 4 weeks previously when he was climbing stairs, and this was relieved by several minutes rest. He also reported that 2 day preceding hospitalization, the pain was triggered by minimum exertion, appearing even at rest. His chest pain was characterized by a squeezing pattern and this was located in the substernal area and it radiated to his left arm. He had no history of hypertension, hypercholesterolemia, diabetes mellitus, smoking and drinking, and there was no history of ischemic heart disease in his family.

Eight years ago he was diagnosed of chronic ITP, but didn't take any treatment. His platelet counts through the years had always been above $60 \times 10^{9} / \mathrm{L}$. This earlier diagnosis of ITP was based on the observation of moderate thrombocytopenia and antiplatelet antibodies, with bone marrow findings consistent with the diagnosis. Five years ago primary PCI was performed in the proximal left anterior descending coronary artery using a drug-eluting stent (DES) because of acute anterior ST-segment elevation myocardial infarction at other hospital. At the time of the first PCI, his platelet count had been around $90 \times 10^{9} / \mathrm{L}$. He received $300 \mathrm{mg}$ of clopidogrel and $300 \mathrm{mg}$ of aspirin along with 5000 units of heparin bolus before PCI. He was discharged on aspirin $100 \mathrm{mg}$ and clopidogrel $75 \mathrm{mg}$ orally daily for 1 year, and he never had bleeding before.

On physical examination, his blood pressure was 135/ $70 \mathrm{mmHg}$. His heart rate was regular at 76 beats $/ \mathrm{min}$. The chest was clear to auscultation and percussion bilaterally. There was no heart murmur. Findings of abdominal and neurological examinations were unremarkable, and lower extremities were without edema. A 12-lead ECG recorded on admission in the patient showed normal sinus rhythm and biphasic or inverted $\mathrm{T}$ waves in leads $\mathrm{V}_{1-3}$ (Fig. 1a). Blood examination revealed a platelet count of $18 \times 10^{9} / \mathrm{L}$, mean platelet volume $13.6 \mathrm{fl}$ (normal range: 6.5-11.0), troponin I level of $0.55 \mathrm{ng} / \mathrm{mL}$ (reference, <0.1), creatine kinase of $105 \mathrm{IU} / \mathrm{L}$ (normal range: $38-171$ ), total cholesterol of $4.47 \mathrm{mmol} / \mathrm{l}$, low density lipoprotein-cholesterol of $1.88 \mathrm{mmol} / \mathrm{l}$, high density lipoprotein-cholesterol of $1.40 \mathrm{mmol} / \mathrm{l}$, triglyceride of $1.29 \mathrm{mmol} / \mathrm{l}$ and fasting blood-glucose of $5.2 \mathrm{mmol} / \mathrm{l}$. Blood coagulation tests showed a prothrombin time of 12.4 s (normal range: 12-15), an international normalized ratio of 0.97 (normal range: 0.85-1.15) and an activated partial thromboplastin time of $35.0 \mathrm{~s}$ (normal: 30-45 s). Brain natriuretic peptide and chest X-ray were normal. A transthoracic echocardiography demonstrated a normal left ventricular end-diastolic internal diameter of $50 \mathrm{~mm}$ with a slightly decreased left ventricular ejection fraction of 0.50. Diagnosis of ACS (acute non-ST-segment elevation myocardial infarction) was made. The GRACE (Global Registry of Acute Coronary Events) risk score of the patient was 143. The patient was administered high doses of intravenous nitroglycerin and oral metrolol and atorvastatin. Ten units of platelets were transfused after the patient was assessed by a hematologist, and the platelet count elevated to $87 \times 10^{9} / \mathrm{L}$ in the second day, and the patient was given $300 \mathrm{mg}$ of aspirin and $300 \mathrm{mg}$ of clopidogrel, prepared for a coronary artery angiography. Bolus injection of 3000 units unfractionated heparin was done at the beginning of the coronary angiography, and the activated clotting time (ACT) was monitored for the dose of heparin required, and then additional 3000 units were added during the PCI procedure, but GP IIb/IIIa inhibitors were not used. Coronary angiography was carried out via the radial artery, and revealed a $95 \%$ in-stent restenosis in the middle part of left anterior descending artery (LAD; Fig. 2a, b). No other lesions were detected. The lesion in 


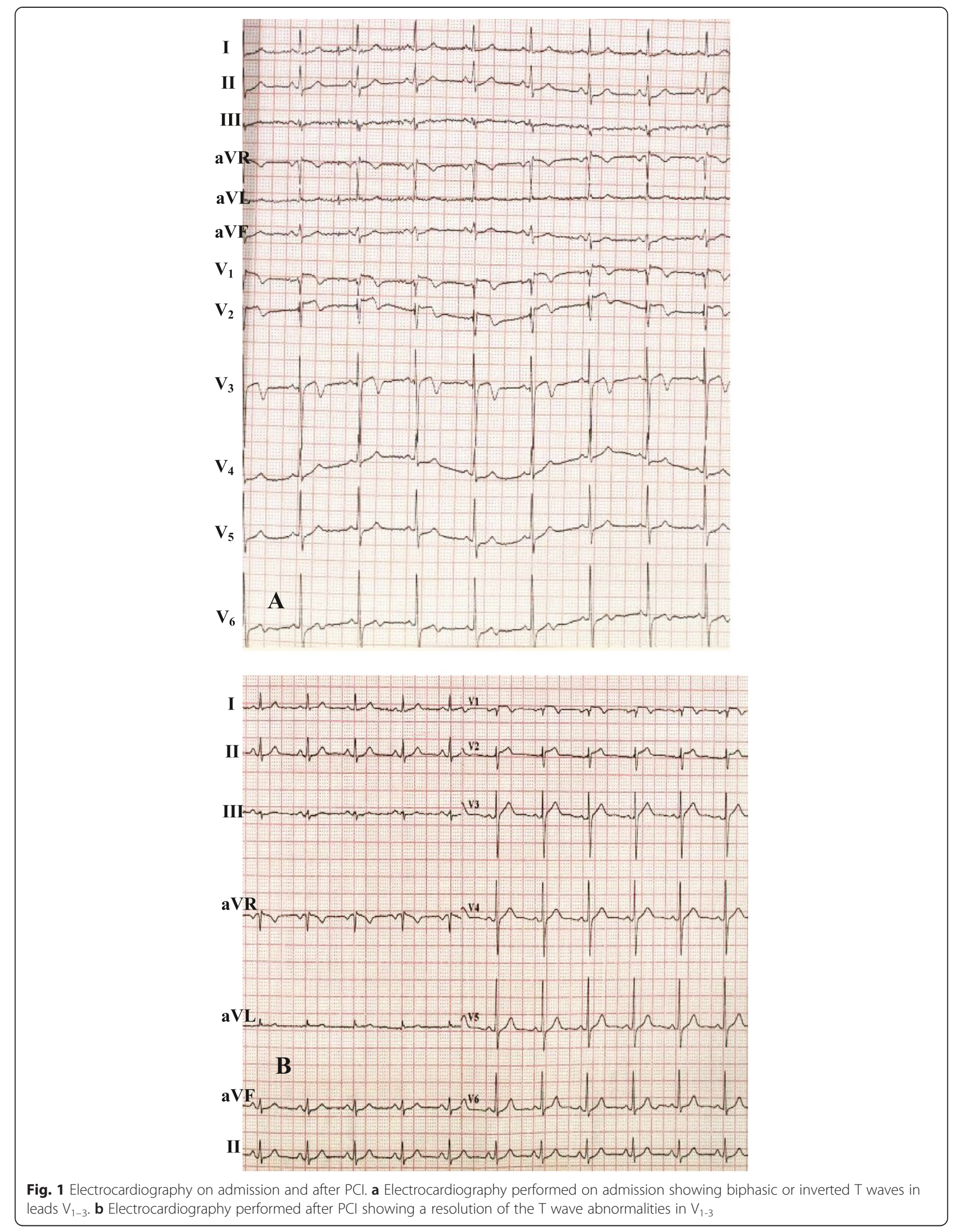



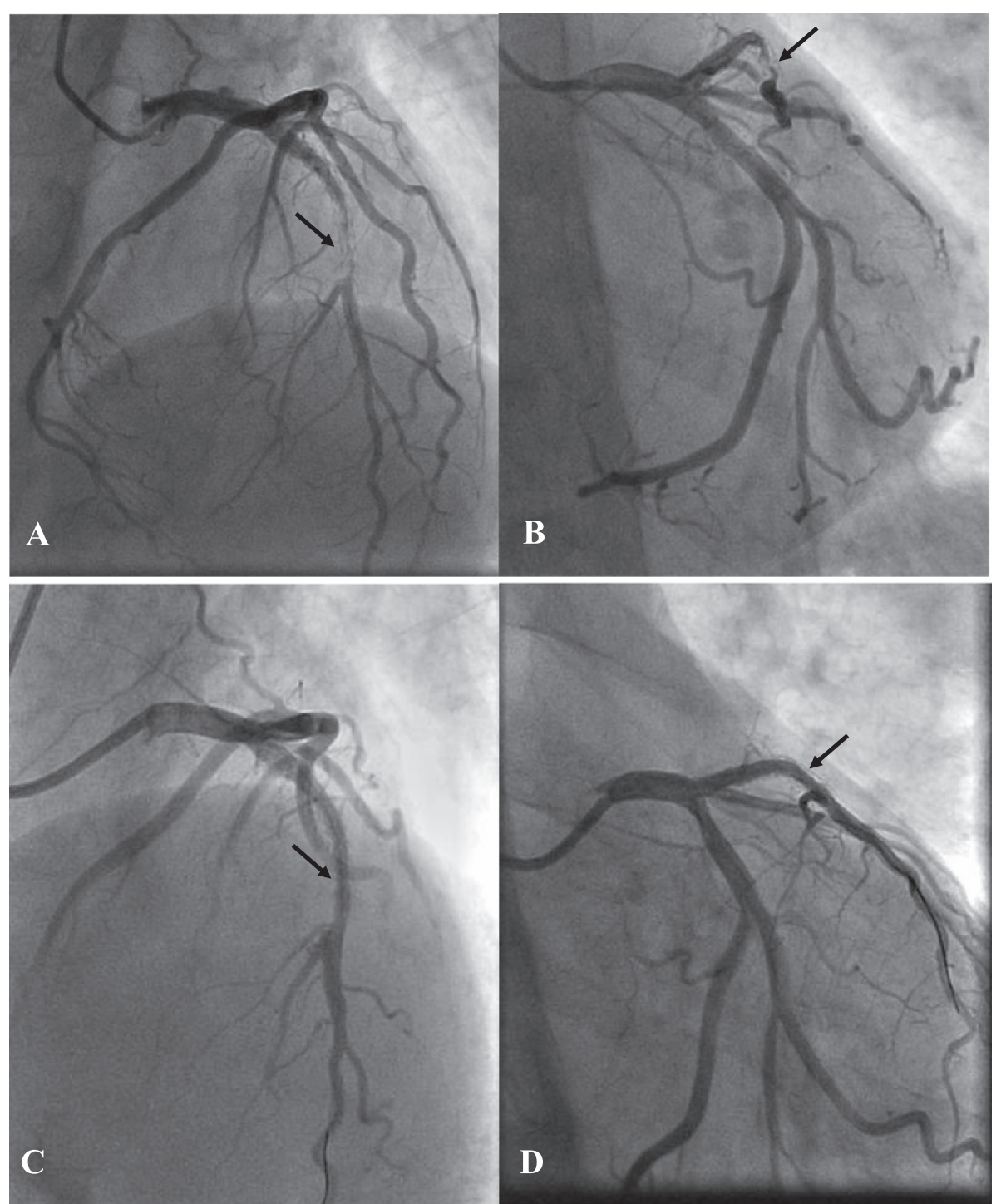

Fig. 2 Coronary angiography in a CRA projection (a) and an RAO + CAU projection (b) showing a severe in-stent restenosis of approximately $95 \%$ in the middle part of left anterior descending artery (arrow). Repeat left coronary angiography following successful cutting balloon angioplasty (arrow) in a CRA projection (c) and an RAO + CAU projection (d)

the left anterior descending artery was treated using a cutting balloon (Boston Scientific) with no complications (Fig. 2c, d). Heparin was not administered any more after the PCI, but combined anti-platelet therapy (aspirin 100 $\mathrm{mg}$ and clopidogrel $75 \mathrm{mg}$ daily) was performed as usual. The ECG showed the $\mathrm{T}$ wave abnormalities in $\mathrm{V}_{1-3}$ were resolved after PCI (Fig. 1b). The patient was discharged asymptomatically at 3 days after PCI. Neither bleeding nor ischemic events were noted during hospitalization.

A week after discharge the platelet count was declined to $27 \times 10^{9} / \mathrm{L}$, and aspirin and clopidogrel were stopped in outpatient clinic. Oral methylprednisolone was begun at $1 \mathrm{mg} / \mathrm{kg}$ per day and tapered over the subsequent 6 weeks. The platelet count gradually recovered to
$200 \times 10^{9} / \mathrm{L}$ after receiving 1 week of methylprednisolone. He continued the treatment with aspirin $100 \mathrm{mg} /$ day, and clopidogrel $75 \mathrm{mg} /$ day for one month without any further problems.

Four months later, the patient was readmitted due to exertional chest pain he had felt for 1 month, even though he took all the medications (aspirin, clopidogrel, metrolol, atorvastatin and oral methylprednisolone) prescribed every day. On admission, the platelet count was $124 \times 10^{9} /$ L, ECG showed normal sinus rhythm and ST segment depression in leads $\mathrm{V}_{2-5}$, and troponin I was mildly elevated $(0.26 \mathrm{ng} / \mathrm{ml}$; reference, $<0.1)$. Diagnosis of unstable angina was made. Coronary angiography showed a $99 \%$ restenosis at the site of the previous 

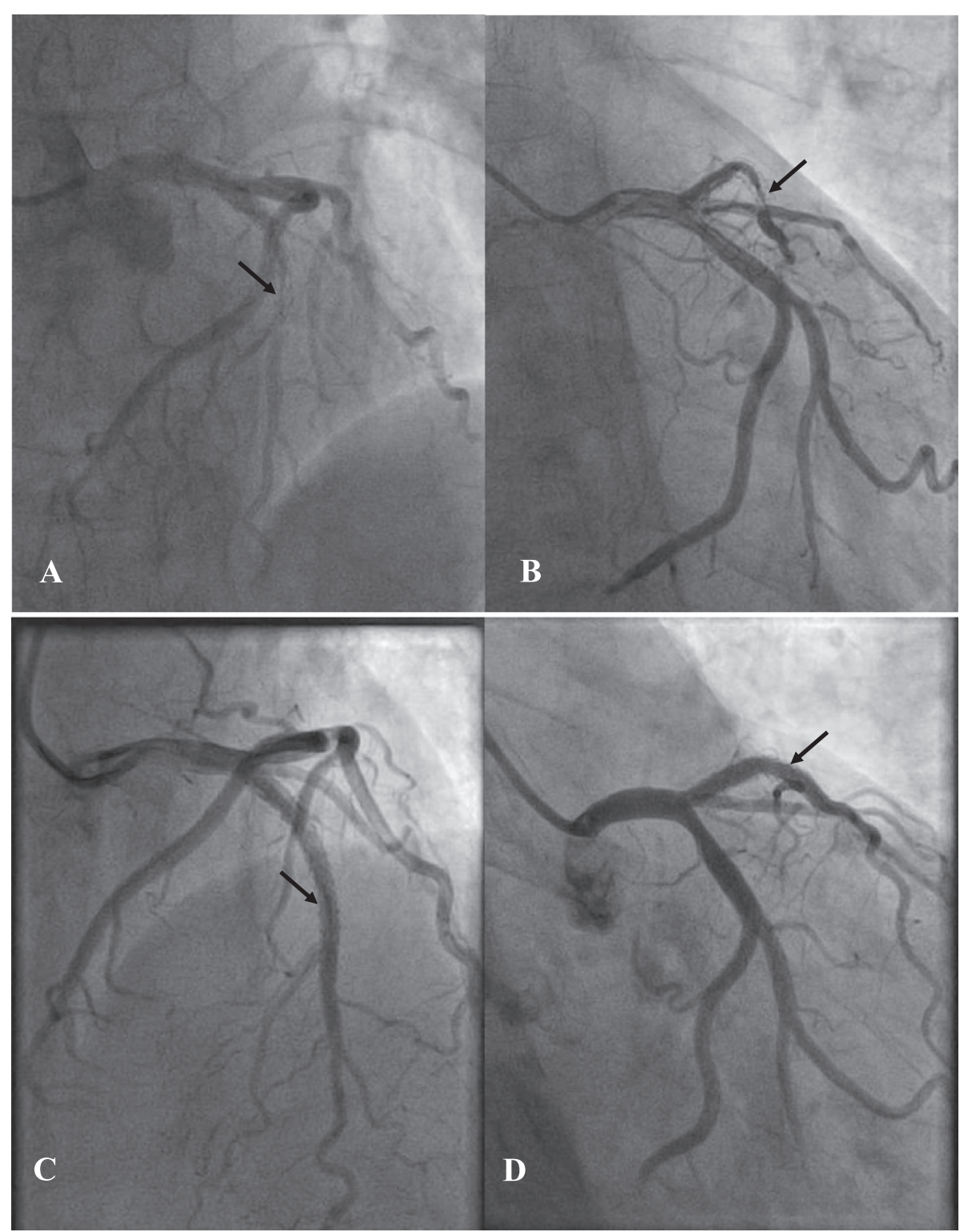

Fig. 3 Coronary angiography in a CRA projection (a) and an RAO + CAU projection (b) showing a severe in-stent restenosis of approximately $99 \%$ in the left anterior descending artery (arrow) 4 months after cutting balloon angioplasty. Repeat left coronary angiography after successful stenting without residual stenosis (arrow) in a CRA projection (c) and an RAO + CAU projection (d)

lesion and a $40 \%$ stenosis in the proximal left circumflex artery (LCX; Fig. 3a, b). We used unfractionated heparin, a dose of $100 \mathrm{U} / \mathrm{kg}$, aspirin $300 \mathrm{mg}$ and clopidogrel $600 \mathrm{mg}$ were administrated. An activated clotting time of $358 \mathrm{~s}$ was achieved. A $3.5 * 28 \mathrm{~mm}$ sirolimus eluted stent was deployed in the LAD with optimal angiographic result and Thrombolysis in Myocardial Infarction (TIMI) flow 3 in the LAD (Fig. 3c, d). There were no bleedings during or after the procedure, and at discharge the platelet count was $203 \times 10^{9} / \mathrm{L}$.

He was then discharged on aspirin, clopidogrel, atorvastatin and oral methylprednisolone. Clopidogrel was discontinued 1 year after the procedure. During 18-month follow-up, the patient remained clinically free of symptoms without any ischemia events or bleeding complications. Coronary angiography showed stent patency at 11 months' follow-up (Fig. 4a, b). The platelet count remained stable.

\section{Results in previous case reports}

Previous reports focusing on ITP patients who underwent PCI were identified by searching PubMed and Google Scholar. Key words used included "ITP", "coronary artery disease", "ACS", "myocardial infarction", "angioplasty", 


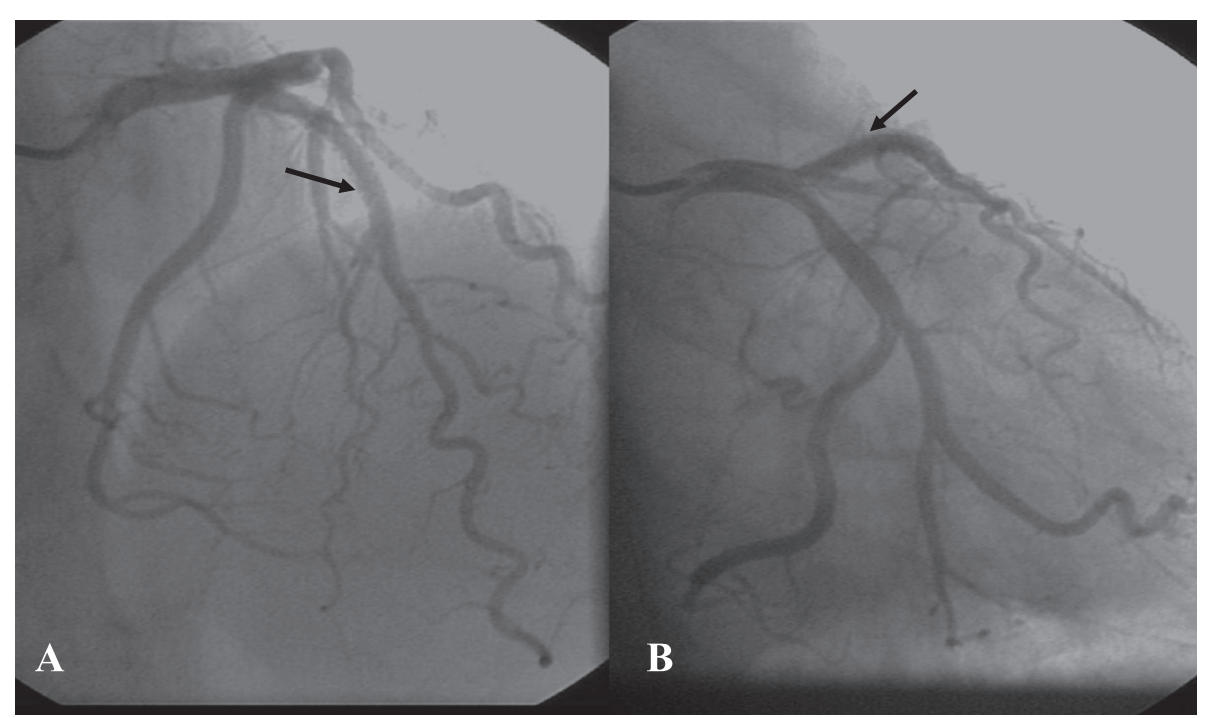

Fig. 4 Coronary angiography in a CRA projection (a) and an RAO + CAU projection (b) showing stent patency 11 months after stenting performed in in-stent restenotic lesion (arrow)

"PCI" and "stent". From 1999 to January 2013, 17 studies involving 18 patients affected by ITP who underwent PCI were reported in the literature (Table 1) [5-21]. The mean age of the patients was $59.7 \pm 15.1$ years (range 23-80 years). Eleven patients were male, and 7 patients were female. Two patients were affected by stable angina, 4 patients by unstable angina, 6 patients by acute non-ST elevation myocardial infarction, and 6 patients by acute ST elevation myocardial infarction. Thirteen patients (72\%) had single vessel coronary artery disease (10 patients for LAD disease, 1 patient for LCX disease, 1 patient for right coronary artery (RCA) disease, 1 patient for obtuse marginal branch disease), 4 patients (22\%) had two-vessel disease, the remaining 1 patient $(6 \%)$ had three-vessel disease. The 18 patients underwent $22 \mathrm{PCI}$ procedures. A total of 29 vessels [15 LAD (51.7 \%), 8 LCX $(27.6 \%), 4$ RCA (13.8 \%), 1 left main coronary artery (LM; $3.4 \%), 1$ obtuse marginal branch of LCX (3.4 \%)] were treated in the $22 \mathrm{PCI}$ procedures. Re-PCI was underwent in 4 patients $(22 \%), 1$ patient because of acute coronary thrombosis [6], 2 patients because of restenosis [10, 15], 1 patient because of staged procedure [17]. Transfemoral and transradial approaches were used for PCI in 12 and 3 patients, respectively, and approach of PCI was not specifed in remaining 3 patients. Only PTCA without subsequent stent placement were underwent in 5 of 22 procedures $(22.7 \%)$, PCI with bare metal stent placement in 13 of 22 procedures (59.1\%), and PCI with drug-eluting stent placement in 4 of 22 procedures (18.2\%). PCI was performed with extremely different platelet counts, ranging from $3 \times 10^{9} / \mathrm{L}$ to $322 \times 10^{9} / \mathrm{L}$ (mean $78.5 \pm 81.5 \times 10^{9} / \mathrm{L}$ ). Glycoprotein IIb/IIIa inhibitors were administrated during PCI in 4 PCI procedures, clopidogrel was administrated before and during $\mathrm{PCI}$ in $9 \mathrm{PCI}$ procedures, ticlopidine in $1 \mathrm{PCI}$ procedure, acetylsalicylic acid in 9 PCI procedures, and no any antiplatelet agents were administrated before and during PCI in 5 PCI procedures. Twelve patients $(66.7 \%)$ received steroid therapy, 10 patients (55.6\%) received intravenous immunoglobulin (IVIG) therapy, and platelet transfusions were completed in 4 patients $(22.2 \%)$. One instance (5.6 \%) of major bleeding (large hematom around the puncture site of the right femoral artery) [6] and 6 of minor bleeding (ecchymoses in 4 patients, small hematoma in 1 patient, diffuse petechiae in 1 patient) were observed. Ten patients (55.6\%) were discharged on double antiplatelet therapy of acetylsalicylic acid and clopidogrel, and 3 patients only on aspirin or ticlopidine, and 3 patients did not receive any antiplatelet agent at discharge. In 2 reports, antiplatelet therapy at discharge was not specifed.

\section{Discussion}

Platelets play an important role in the atherosclerotic process and are intrinsically involved in the pathogenesis of ACS [1-3]. Thrombocytosis has been correlated with high incidence of ischemic heart disease, such as acute myocardial infarction [22]. Since platelets play a major role in thrombotic events, the association of ITP and ACS is rare. Nevertheless, acute myocardial infarction has been reported in even severely thrombocytopenic patients [5]. This implies that some factor other than platelet numbers alone is involved. 
Table 1 Case reports on percutaneous coronary intervention in patients with idiopathic thrombocytopenic purpura

\begin{tabular}{|c|c|c|c|c|c|c|c|c|c|c|}
\hline Study & $\begin{array}{l}\text { Pt age }(Y) \\
\text { and sex }\end{array}$ & CAD & $\begin{array}{l}\text { Pre-PCIPLT } \\
\text { count }\left(\times 10^{9} / \mathrm{L}\right)\end{array}$ & $\begin{array}{l}\text { Antiplatelet agent } \\
\text { before and during } \mathrm{PCl}\end{array}$ & Treated vessels & $\mathrm{PCl}$ and approach & Treatment of ITP & Bleeding & Restenosis & Discharge therapy \\
\hline \multirow{2}{*}{$\begin{array}{l}\text { Fuchi et al., } \\
1999 \text { [20] (twice) }\end{array}$} & \multirow[t]{2}{*}{$72, F$} & NSTEMI & 59 & None & $\angle A D$ & PTCA, Femoral & STER & Large hematoma & NA & \multirow[t]{2}{*}{ None } \\
\hline & & STEMI & 23 & None & LAD & PTCA, Femoral & STERIVIGPLTT & No & NA & \\
\hline $\begin{array}{l}\text { Caputo et al., } \\
2000 \text { [6] }\end{array}$ & $62, \mathrm{M}$ & Unstable angina & 3 & NA & LAD & $\begin{array}{l}\text { BMS stenting, } \\
\text { Radial }\end{array}$ & STER & No & NA & ASA Clop \\
\hline $\begin{array}{l}\text { Segal et al., } \\
2001 \text { [21] }\end{array}$ & $49, \mathrm{M}$ & NSTEMI & 41 & ASAClopAbciximab & RCA, LCX & $\begin{array}{l}\text { BMS stenting, } \\
\text { Femoral }\end{array}$ & STER & No & NA & ASA Clop \\
\hline $\begin{array}{l}\text { Kikuchi et al., } \\
2002 \text { [22] }\end{array}$ & $68, F$ & STEMI & 22 & Ticlopidine & LAD & $\begin{array}{l}\text { BMS stenting, } \\
\text { Femoral }\end{array}$ & NA & No & No & Ticlopidine \\
\hline $\begin{array}{l}\text { Méndez et al., } \\
2004 \text { [23] }\end{array}$ & $70, M$ & NSTEMI & 170 & ASAClopAbciximab & RCA, LCX & $\begin{array}{l}\text { BMS stenting, } \\
\text { Radial }\end{array}$ & IVIGPLTT & ECC & NA & NA \\
\hline \multirow{2}{*}{$\begin{array}{l}\text { Stouffer et al., } \\
2004 \text { [24] (twice) }\end{array}$} & \multirow[t]{2}{*}{$77, \mathrm{M}$} & Unstable angina & 64 & ASA & LCX & PTCA & None & No & yes & ASA \\
\hline & & NSTEMI & 78 & ASA Eptifibatide & LCX & BMS stenting & STER & Petechiae & No & ASA Clop \\
\hline $\begin{array}{l}\text { Amit et al., } \\
2005 \text { [25] }\end{array}$ & $46, M$ & NSTEMI & 38 & ASA & $L A D$ & PTCA & IVIG & No & NA & ASA \\
\hline $\begin{array}{l}\text { Marques et al., } \\
2005 \text { [26] }\end{array}$ & $54, \mathrm{M}$ & Unstable angina & 15 & None & LAD, LCX & $\begin{array}{l}\text { BMS stenting, } \\
\text { Brachial }\end{array}$ & STERIVIGPLTT & No & NA & None \\
\hline $\begin{array}{l}\text { Kim et al., } \\
2006 \text { [27] }\end{array}$ & $47, F$ & STEMI & 21 & Clop & RCA & $\begin{array}{l}\text { BMS stenting, } \\
\text { Femoral }\end{array}$ & IVIG & ECC & NA & ASA Clop \\
\hline $\begin{array}{l}\text { Fong et al., } \\
2006 \text { [28] }\end{array}$ & $71, F$ & NSTEMI & 119 & ASA & LAD & $\begin{array}{l}\text { DES stenting, } \\
\text { Radial }\end{array}$ & STERIVIG & No & No & ASA Clop \\
\hline \multirow{3}{*}{$\begin{array}{l}\text { Park et al., } 2007 \\
\text { [29] } 3 \text { times }\end{array}$} & \multirow[t]{3}{*}{$61, F$} & \multirow[t]{3}{*}{ Stable angina } & 4 & None & None & CAG, Femoral & STER & Hematoma & No & None \\
\hline & & & 34 & None & LAD, LCX & $\begin{array}{l}\text { BMS stenting, } \\
\text { Femoral }\end{array}$ & STERIVIGPLTT & No & yes & None \\
\hline & & & 20 & None & LAD, LCX & PTCA, Femoral & STER & No & NA & None \\
\hline $\begin{array}{l}\text { Gracia et al., } \\
2008 \text { [30] }\end{array}$ & $37, M$ & STEMI & 39 & ASA Clop & LAD & $\begin{array}{l}\text { BMS stenting, } \\
\text { Femoral }\end{array}$ & None & No & NA & ASA Clop \\
\hline \multirow{2}{*}{$\begin{array}{l}\text { Moretti et al., } \\
2008 \text { [31] (twice) }\end{array}$} & \multirow[t]{2}{*}{$66, M$} & \multirow[t]{2}{*}{ Unstable angina } & 110 & NA & RCA, LCX & BMS stenting & STERIVIG & No & NA & ASA Clop \\
\hline & & & 200 & NA & LM, LAD & $\begin{array}{l}\text { DES stenting, } \\
\text { Femoral }\end{array}$ & STER & No & NA & ASA Clop \\
\hline $\begin{array}{l}\text { Can et al., } \\
2009 \text { [32] }\end{array}$ & $76, M$ & Stable angina & 100 & Clop & $\angle A D$ & $\begin{array}{l}\text { BMS stenting, } \\
\text { Femoral }\end{array}$ & Danazol & No & NA & NA \\
\hline $\begin{array}{l}\text { Yildiz et al., } \\
2010 \text { [33] }\end{array}$ & $23, F$ & STEMI & 35 & Clop & LAD & $\begin{array}{l}\text { BMS stenting, } \\
\text { Femoral }\end{array}$ & STER & ECC & NA & ASA Clop \\
\hline
\end{tabular}


Table 1 Case reports on percutaneous coronary intervention in patients with idiopathic thrombocytopenic purpura (Continued)

\begin{tabular}{|c|c|c|c|c|c|c|c|c|c|c|}
\hline $\begin{array}{l}\text { Neskovic et al., } \\
2010 \text { [34] }\end{array}$ & $80, M$ & STEMI & 5 & ASA Clop & $\mathrm{LAD}$ & $\begin{array}{l}\text { BMS stenting, } \\
\text { Femoral }\end{array}$ & STER Danazol & No & NA & ASA Clop \\
\hline \multirow[t]{2}{*}{$\begin{array}{l}\text { Torbey et al., } 2013 \\
\text { [35] } 2 \text { cases }\end{array}$} & $61, F$ & STEMI & 322 & ASA Clop Abciximab & $\mathrm{LAD}$ & $\begin{array}{l}\text { DES stenting, } \\
\text { Femoral }\end{array}$ & SPLSTERIVIG & ECC & NA & ASA Clop \\
\hline & $55, \mathrm{M}$ & NSTEMI & 208 & Clop & $\begin{array}{l}\text { Obtusemarginal } \\
\text { branch }\end{array}$ & $\begin{array}{l}\text { DES stenting, } \\
\text { Femoral }\end{array}$ & STERIVIG & No & yes & ASA Clop \\
\hline
\end{tabular}

Pt patient, $Y$ years, $F$ femal, $M$ male, CAD coronary artery disease, NSTEMI non-ST elevation myocardial infarction, STEMI ST elevation myocardial infarction, PCI percutaneous coronary intervention, PLT Platelet, NA data not available, ASA acetylsalicylic acid, Clop clopidogrel, LAD left anterior descending artery, RCA right coronary artery, $L C X$ left circumflex artery, LM left main artery, PTCA Percutaneous transluminal coronary angioplasty, not available, ASA acetylsalicylic acid, Clop clopidogrel, LAD left anterior descending artery, RCA right coronary artery, LCX left circumflex artery, LM left main artery, PTCA Percutaneous transluminal co
$B M S$ bare metal stent, DES drug-eluting stent, ITP idiopathic thrombocytopenic purpura, STER steroids, IVIG intravenous immunoglobulin, PLIT Platelets transfusion, SPL Splenectomy, ECC Ecchymoses 
If a patient with chronic thrombocytopenia has coronary artery disease, the concomitance of known coronary risk factors, such as hypertension, diabetes, dyslipidemia, cigarette smoking or a family history for cardiovascular disease, should be considered. Sometimes, in patients without these coronary risk factors like the present case, it could be related with some other causes. First, platelets in patients with ITP was larger, younger, and more adhesive to the vascular surface [23]. In acute myocardial infarction or stroke patients, mean platelet volume is significantly increased despite a concomitant decrease in platelet count [24-26]. In the present case, the mean platelet volume of the patient was significantly increased. Previous studies have demonstrated that large platelets have a higher thrombotic potential [24-26]. Osuna et al [27] analysed the relationship between mean platelet volume and recurrent myocardial infarction, and found that increased mean platelet volume and platelet size contributed to reinfarction and death. Karpatkin [28] reported that the platelet aggregation velocity was directly in proportion to the platelet volume and correlated best with the megathrombocyte index. Second, elevated platelet microparticles in the ITP patients with ACS were observed $[29,30]$. Microparticles are membrane vesicles released from many different cell types, including platelets. They have a potent pro-inflammatory effect, promote coagulation and affect vascular function [29, 30]. Circulating platelet microparticles and the risk of thromboembolic complications have repeatedly been demonstrated [29-31]. Therefore, platelet microparticles may be associated with coronary thrombosis in patients with ITP. Third, antigenic mimicry between platelets and endothelial cells may lead to damage of the platelets and the endothelium, caused by autoantibodies directed against platelet surface antigens, notably IIb/IIIa receptors [32, 33]. Finally, a rise of the platelet count with administration of steroids, intravenous immunoglobulin, or platelet transfusion in ITP might be "procoagulant" and might aggravate the potentially adverse effect of increased plasma viscosity leading to increased susceptibility to fatal thrombotic events, such as myocardial infarction or stroke [23, 34, 35].

The combination of ITP and coronary artery disease poses serious management problems in which a good balance between the prevention of thrombosis and hemorrhagic risk must be achieved. Indeed, ITP increases risks of bleeding in general and medications to inhibit platelet function are generally not recommended. However, antiplatelet agents should be used in patients with coronary artery disease unless contraindication exists, especially after stent implantation. This dilemma leads to difficulty in managing concomitant ITP and coronary artery disease. Performance of PCI in a patient with ITP presents a unique situation in which platelet function needs to be inhibited sufficiently to perform PCI safely but not to the extent that bleeding complications result. Our initial strategy was to treat the patient with drugs, but our patient had refractory symptoms and ischemic ECG changes and elevated troponin I despite therapy with nitrates, $\beta$-blockers and statins, and revascularization was, therefore, indicated. Since our patient was categorized as having high risk for major bleeding and had only a single coronary lesion, PCI was a better choice than bypass surgery. We decided to administer antiplatelet agents after platelets transfusion, and then proceed using cutting balloon angioplasty without stent implantation because of the risk of subacute stent thrombosis in a patient in whom it was unknown whether he would be tolerant of combination therapy of acetylsalicylic acid and clopidogrel after stent implantation. The patient was given steroids following cutting balloon angioplasty, and the platelet count increased and remained normal level. The patient did receive an intracoronary stent 4 months later when he once again presented with recurrent ACS in the setting of restenosis. Coronary angiography showed stent patency 11 months after stent implantation.

Based on the results of the previous case reports [5-21, 31, 36] and present report, we concluded that PCI can be a useful strategy in patients with ITP and severe coronary artery disease even when the patient has severe thrombocytopenia, and major bleeding was rare. Both transfemoral and transradial approaches were successfully used for PCI. Implanting a bare metal stent (BMS) appears to be reasonable choice during $\mathrm{PCI}$, since dual antiplatelet therapy with acetylsalicylic acid and clopidogrel could be administered for a shorter period of time to allow stent endothelialization. DES implantation was also reported in 4 patients, and 5 cases of PCI without subsequent stent placement were also reported. Perioperative ITP treatment certainly minimized the complication rate in the PCI population as well. Steroids should be first choice to increase the platelet count, but if a rapid platelet count elevation were required, platelet transfusions and IVIG supplementation could be administered. A safe cutoff platelet count above which invasive procedures can be performed has not been yet established. Russo et al. [36] have suggested that when the platelet counts $>50 \times 10^{9} / \mathrm{L}$ intervention either percutaneously or surgically can be safely performed. The combined therapy of acetylsalicylic acid and clopidogrel after PCI was well tolerated in most of patients. In addtion, most of patients had single vessel coronary artery disease and LAD artery was the most commonly occluded of the coronary arteries in patient with ITP, which was the same with the general population. Among 7 cases who underwent reexamined coronary angiography, 3 patients had coronary restenosis. The restenosis developed after percutaneous transluminal coronary angioplasty without 
stent placement in 1 patient, after BMS implant in 1 patient, and after DES implant in 1 patient. The present case also occurred repeatedly in-stent restenosis. Repeat revascularization was successfully done in all 4 patients. Many factors may be involved in the pathophysiology of restenosis. Norgaz et al [37] found that mean platele volume before PCI is correlated with subsequent development of in-stent restenosis, and if preprocedural mean platele volume is greater than $8.4 \mathrm{fl}$, restenosis is more probable to occur. Generally, The mean platelet volume in patients with ITP was significantly increased. Therefore, platelet size may play a role in the development of restenosis after PCI in a patient with ITP.

\section{Conclusions}

Available data suggest that PCI can be safe and feasible, and the risk-benefit equation of PCI procedures and antiplatelet therapies should be carefully evaluated, and the treatment should be individualized.

\section{Consent statement}

Written informed consent was obtained from the patient for publication of this case report and any accompanying images.

\begin{abstract}
Abbreviations
ACS: Acute coronary syndrome; ACT: Activated clotting time; BMS: Bare metal stent; DES: Drug-eluting stent; GRACE: Global Registry of Acute Coronary Events; ITP: Idiopathic thrombocytopenic purpura; IVIG: Intravenous immunoglobulin; LAD: Left anterior descending artery; LCX: Left circumflex artery; PCI: Percutaneous coronary intervention; RCA: Right coronary artery; TIMI: Thrombolysis in Myocardial Infarction.
\end{abstract}

Competing interests

The authors declare that they have no competing interests.

\section{Authors' contributions}

LYC and CP performed the PCI and helped writing the paper. GLS wrote the paper. All authors read and approved the final manuscript.

\section{Author details \\ 'Department of Pediatric, Second Affiliated Hospital of Wenzhou Medical University, Wenzhou 325000, China. ${ }^{2}$ Department of Cardiology, Second Affiliated Hospital of Wenzhou Medical University, 109 Xueyuan Road, Wenzhou, Zhejiang, China.}

Received: 9 October 2014 Accepted: 12 September 2015

Published online: 18 September 2015

\section{References}

1. Ault KA, Cannon CP, Mitchell J, McCahan J, Tracy RP, Novotny WF, et al. Platelet activation in patients after an acute coronary syndrome: results from the TIMI-12 trial. Thrombolysis in Myocardial Infarction. J Am Coll Cardiol. 1999;33:634-9.

2. Giugliano RP, Braunwald E. The year in acute coronary syndrome. J Am Coll Cardiol. 2014;63:201-14.

3. Varenhorst C, Jensevik K, Jernberg T, Sundström A, Hasvold P, Held C, et al. Duration of dual antiplatelet treatment with clopidogrel and aspirin in patients with acute coronary syndrome. Eur Heart J. 2014;35:969-78.

4. Cines DB, Blanchette VS. Immune thrombocytopenic purpura. N Engl J Med. 2002;346:995-1008.
5. Caputo RP, Abraham S, Churchill D. Transradial coronary stent placement in a patient with severe idiopathic autoimmune thrombocytopenic purpura. J Invasive Cardiol. 2000;12:365-8.

6. Fuchi T, Kondo T, Sase K, Takahashi M. Primary percutaneous transluminal coronary angioplasty performed for acute myocardial infarction in a patient with idiopathic thrombocytopenic purpura. Jpn Circ J. 1999;63:133-6.

7. Segal OR, Baker CS, Banim S. Percutaneous coronary intervention with adjunctive abciximab and clopidogrel in a patient with chronic idiopathic thrombocytopaenic purpura. Int J Cardiovasc Intervent. 2001;4:35-8.

8. Kikuchi S, Hayashi Y, Fujioka S, Kukita H, Ochi N. A case of intracoronary stent implanted for acute myocardial infarction in an elderly patient with idiopathic thrombocytopenic purpura. Nippon Ronen Igakkai Zasshi. 2002;39:88-93.

9. Méndez TC, Díaz Ó, Enríquez L, Baz JA, Fernández F, Goicolea J. Severe thrombocytopenia refractory to platelet transfusion secondary to abciximab readministration in a patient previously diagnosed with idiopathic thrombocytopenic purpura A possible etiopathogenic link. Rev Esp Cardiol. 2004;57:789-91.

10. Stouffer GA, Hirmerova J, Moll S, Rubery B, Napoli M, Ohman EM, et al. Percutaneous coronary intervention in a patient with immune thrombocytopenia purpura. Catheter Cardiovasc Interv. 2004;61:364-7.

11. Amit G, Yermiyahu T, Gilutz H, Ilia R, Zahger D. Thrombocytopenia, immunoglobulin treatment, and acute myocardial infarction-a case report. Angiology. 2005;56:229-31.

12. Marques LG, Furukawa MK, Leitão TP, Quiñones $\mathrm{L}$, Queiroz FC, Tiossi RF, et al. Percutaneous transluminal coronary angioplasty in a patient with idiopathic thrombocytopenic purpura. Arq Bras Cardiol. 2005;84:337-9.

13. Kim JH, Park KU, Chum WJ, Kim SH, Nah DY. Primary percutaneous coronary intervention for acute myocardial infarction with idiopathic thrombocytopenic purpura: a case report. J Korean Med Sci. 2006;21:355-7.

14. Fong MC, Chen KC, Leu HB, Chen LC. Coronary revascularization in a patient with immune thrombocytopenic purpura. J Chin Med Assoc. 2006;69:436-8.

15. Park HJ, Seung KB, Kim PJ, Kang HH, Park CS, Kil UH, et al. Intracoronary stent deployment without antiplatelet agents in a patient with idiopathic thrombocytopenic purpura. Korean Circ J. 2007;37:87-90.

16. Gracia MC, Cebollero IC, Lezcano JS, Osuna GG, Miguel JA, Peralta LP. Invasive treatment performed for acute myocardial infarction in a patient with immune thrombocytopenic purpura. Int J Cardiol. 2008;127:183-5

17. Moretti C, Teresa Lucciola M, Morena L, Biondi-Zoccai G, Laudito A, Anselmino $\mathrm{M}$, et al. Idiopathic thrombocytopenic purpura and percutaneous coronary stenting: a dangerous duo? Int J Cardiol. 2008;130:e96-7.

18. Can MM, Tanboga IH, Boztosun B, Kaymaz C. Antiplatelet treatment after percutaneous coronary intervention in a patient with idiopathic thrombocytopenic purpura. Arch Turk Soc Cardiol. 2009:37:575-7.

19. Yildiz A, Coskun U, Batukan OE, Keskin K. Primary percutaneous coronary intervention for acute myocardial infarction in a young female with idiopathic thrombocytopenic purpura: a case report and review. Case Rep Med. 2010;2010:854682.

20. Neskovic A, Stankovic I, Milicevic P, Aleksic A, Vlahovic-Stipac A, Calija B, et al. Primary $\mathrm{PCl}$ for acute myocardial infarction in a patient with idiopathic thrombocytopenic purpura. Herz. 2010;35:43-9.

21. Torbey E, Yacoub H, McCord D, Lafferty J. Two cases and review of the literature: primary percutaneous angiography and antiplatelet management in patients with immune thrombocytopenic purpura. ISRN Hematol. 2013;2013:174659.

22. Nanavati A, Patel N, Burke J. Thrombocytosis and coronary occlusion. JACC Cardiovasc Interv. 2012;5:e18-9.

23. Rand ML, Dean JA. Platelet function in autoimmune (idiopathic) thrombocytopenic purpura. Acta Paediatr Suppl. 1998;424:57-60.

24. Martin JF, Bath PM, Burr ML. Influence of platelet size on outcome after myocardial infarction. Lancet. 1991;338:1409-11.

25. Endler G, Klimesch A, Sunder-Plassmann H, Schillinger M, Exner M, Mannhalter

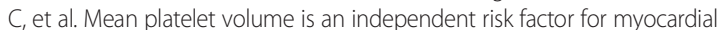
infarction but not for coronary artery disease. Br J Haematol. 2002;117:399-404.

26. Furiozzi F. Mean platelet volume and acute ischemic stroke. Stroke. 1996;27:1010-1.

27. Pabón Osuna P, Nieto Ballesteros F, Moríñigo Muñoz JL, Sánchez Fernández PL, Arribas Jiménez A, Diego Domínguez M, et al. The effect 
of the mean platelet volume on the short-term prognosis of acute myocardial infarct. Rev Esp Cardiol. 1998;51:816-22.

28. Karpatkin S. Heterogeneity of human platelets. VI. Correlation of platelet function with platelet volume. Blood. 1978;51:307-16.

29. VanWijk MJ, VanBavel E, Sturk A, Nieuwland R. Microparticles in cardiovascular diseases. Cardiovasc Res. 2003;59:277-87.

30. Puddu P, Puddu GM, Cravero E, Muscari S, Muscari A. The involvement of circulating microparticles in inflammation, coagulation and cardiovascular diseases. Can J Cardiol. 2010;26:140-5.

31. Yusuf SW, lliescu C, Bathina JD, Daher IN, Durand JB. Antiplatelet therapy and percutaneous coronary intervention in patients with acute coronary syndrome and thrombocytopenia. Tex Heart Inst J. 2010;37:336-3340

32. Thiagarajan $\mathrm{P}$, Shapiro SS, Levine E, DeMarco L, Yalcin A. A monoclonal antibody to human platelet glycoprotein Illa detects a related protein in cultured human endothelial cells. J Clin Invest. 1985;75:896-901.

33. Leeksma OC, Zandbergen-Spaargaren J, Giltay JC, van Mourik JA. Cultured human endothelial cells synthesize a plasma membrane protein complex immunologically related to the platelet glycoprotein IIb/llla complex. Blood. 1986:67:1176-80.

34. Woodruff RK, Grigg AP, Firkin FC, Smith IL. Fatal thrombotic events during treatment of autoimmune thrombocytopenia with intravenous immunoglobulin in elderly patients. Lancet. 1986;2:217-8.

35. Paolini R, Zamboni S, Ramazzina E, Zampieri P, Cella G. Idiopathic thrombocytopenic purpura treated with steroid therapy does not prevent acute myocardial infarction: a case report. Blood Coagul Fibrinolysis. 1999:10:439-42.

36. Russo A, Cannizzo M, Ghetti G, Barbaresi E, Filippini E, Specchia S, et al. Idiopathic thrombocytopenic purpura and coronary artery disease: comparison between coronary artery bypass grafting and percutaneous coronary intervention. Interact Cardiovasc Thorac Surg. 2011;13:153-7.

37. Norgaz T, Hobikoglu G, Aksu H, Bolca O, Uyarel H, Eren M, et al. The relationship between preprocedural platelet size and subsequent in-stent restenosis. Acta Cardiol. 2004:59:391-5.

\section{Submit your next manuscript to BioMed Central and take full advantage of:}

- Convenient online submission

- Thorough peer review

- No space constraints or color figure charges

- Immediate publication on acceptance

- Inclusion in PubMed, CAS, Scopus and Google Scholar

- Research which is freely available for redistribution 